\title{
ARTICLE
}

\section{Neuronal adaptation involves rapid expansion of the action potential initiation site}

\author{
Ricardo S. Scott ${ }^{1,2, \star}$, Christian Henneberger ${ }^{1,3, \star}$, Ragunathan Padmashri ${ }^{1, \star}, \uparrow$, Stefanie Anders ${ }^{3}$, \\ Thomas P. Jensen ${ }^{1} \&$ Dmitri A. Rusakov ${ }^{1}$
}

Action potential (AP) generation is the key to information-processing in the brain. Although APs are normally initiated in the axonal initial segment, developmental adaptation or prolonged network activity may alter the initiation site geometry thus affecting cell excitability. Here we find that hippocampal dentate granule cells adapt their spiking threshold to the kinetics of the ongoing dendrosomatic excitatory input by expanding the AP-initiation area away from the soma while also decelerating local axonal spikes. Dual-patch soma-axon recordings combined with axonal $\mathrm{Na}^{+}$and $\mathrm{Ca}^{2+}$ imaging and biophysical modelling show that the underlying mechanism involves distance-dependent inactivation of axonal $\mathrm{Na}^{+}$ channels due to somatic depolarization propagating into the axon. Thus, the ensuing changes in the AP-initiation zone and local AP propagation could provide activity-dependent control of cell excitability and spiking on a relatively rapid timescale.

\footnotetext{
${ }^{1}$ UCL Institute of Neurology, University College London, Queen Square, WC1N 3BG London, UK. ${ }^{2}$ Instituto de Neurociencias de Alicante, Universidad Migue Hernández-CSIC, Campus de San Juan, Sant Joan d'Alacant, 03550 Alicante, Spain. ${ }^{3}$ Institute of Cellular Neurosciences, University of Bonn Medical School, D-53105 Bonn, Germany. *These authors contributed equally to this work. †Present address: University of Nebraska Medical Center, Omaha, Nebraska 68198, USA. Correspondence and requests for materials should be addressed to D.A.R. (email: d.rusakov@ucl.ac.uk) or to R.S.S. (email: sscott@umh.es) or to C.H. (email: christian.henneberger@ukb.uni-bonn.de).
} 
ntegration of synaptic inputs leading to initiation and propagation of action potentials (APs) provides the basic machinery of information encoding and transfer in neural circuits. The spike generation threshold, however, could vary depending on the history and dynamics of the cell membrane potential, in vitro and in vivo ${ }^{1-6}$. In most cases, the cell AP threshold is inversely correlated with the rate of dendrosomatic depolarization, thus providing a clear informational advantage for synchronized input, or for successful coincidence detection, in the microcircuits of the brain ${ }^{7-9}$. However, the cellular machinery underlying this basic adaptation mechanism, including the contributions of somatic and axonal spike initiation, remains under debate.

In most neuronal types, APs are initiated within the axon initial segment, or the first node of Ranvier in myelinated axons, which is normally associated with a hotspot of $\mathrm{Na}^{+}$ channels ${ }^{10-14}$, although there have been observations suggesting otherwise $^{15,16}$. Intriguingly, recent studies have shown that the axonal AP-initiation zone could be modified, on the timescale of hours or days, by sustained network activity ${ }^{17,18}$. Such modification has a strong adaptive significance because the position and geometry of the AP-initiation zone reflect the ability of the host neuron to recognize specific spiking patterns, and thus to filter or encode specific network information ${ }^{19}$. At the same time, high-sensitivity voltage imaging in myelinated axons of cortical neurons has indicated stability of the spike-initiation site over shorter timescales ${ }^{20}$, and little threshold variability has been attributed to the axonal spike-initiation mechanism in the cortex ${ }^{6}$. Nonetheless, a very recent study in cortical cells, which combined dual-patch soma-axon recordings with axonal $\mathrm{Na}^{+}$ imaging, predicted that minor changes in the $\mathrm{Na}^{+}$channel distribution in the proximal axon could have a strong effect on neuronal excitability ${ }^{16}$. This basic phenomenon was not intuitively understood in the past and may have fundamental implications of our understanding of cell excitability ${ }^{21}$.

To understand how short-term plasticity influences cell excitability, here we focus on spike generation in non-myelinated axons of hippocampal dentate granule cells (mossy fibres, MFs), which represent a major excitatory pathway into area CA3 and exhibit extraordinary use- and target cell-dependent plasticity ${ }^{22-25}$. Previous MF studies, which utilized presynaptic $\mathrm{Ca}^{2+}$ imaging ${ }^{26}$, whole-terminal configuration ${ }^{27}$ and soma-axon dual-patch recording ${ }^{25}$, have indicated significant electrotonic propagation of somatic voltage into these axons. These observations indirectly suggested that excitatory input may influence channel mechanisms of axonal spike initiation in the proximal axon in a distance-dependent manner. This basic biophysical phenomenon has not been reported previously, even though depolarization-dependent inactivation of axonal $\mathrm{Na}^{+}$ and $\mathrm{K}^{+}$channels in MFs has been documented in detail using whole-terminal or axonal outside-out patch recordings ${ }^{28,29}$. Here we report that reducing the pace of excitatory synaptic input to granule cell dendrites does elevate the spiking threshold of the cell. We use dual-patch soma-axon recordings and axonal $\mathrm{Na}^{+}$ and $\mathrm{Ca}^{2+}$ imaging to conclude that the underlying mechanism relies on depolarization-dependent partial inactivation of axonal $\mathrm{Na}^{+}$channels, which weakens with greater distances from the soma. This inactivation leads to the site of AP initiation being expanded, spreading away from the soma and decelerating local spikes. Our experimental observations appear consistent with predictions of a detailed biophysical NEURON model of a reconstructed granule cell and Monte Carlo tests. We conclude that rapid use-dependent changes in the spread of the axonal area where APs can be initiated provide the mechanism by which a principal neuron can adapt its information-handling properties to the ongoing excitatory activity.

\section{Results}

Dendritic excitation controls the granule cell-spiking threshold. We held granule cells in whole-cell mode (current clamp) and stimulated perforant path fibres with an extracellular electrode, $>200 \mu \mathrm{m}$ away from the recorded cell, using a $100-\mathrm{Hz}$ train of 10 stimuli (Fig. 1a; temperature $\sim 33^{\circ} \mathrm{C}$; $\mathrm{GABA}_{\mathrm{A}}$ blocked). Stimulation-induced synaptic discharges led to somatic depolarization that was sufficient for the cell to fire, and we varied the stimulus strength from trial to trial so that the rise time of somatic depolarization before the first AP ranged from 5-8 to $100-200 \mathrm{~ms}$. This type of granule cell activity is well within the range documented in behaving animals ${ }^{30}$. We found that in every tested cell, the spiking threshold increased robustly when the depolarization rate was slowed down (Fig. 1b,c). This was not due to homoeostatic changes or use-dependent plasticity in the circuitry because trials with slower and faster depolarization were recorded in an arbitrarily sequence. The maximum increase in the spiking threshold due to deceleration of excitation was $5-8 \mathrm{mV}$ across the sample (Fig. 1). As these cells required a depolarization of $15-30 \mathrm{mV}$ above the resting potential (approximately $-75 \mathrm{mV}$ ) to generate an AP, our data indicated that accelerating the excitatory input had an effect roughly equivalent to the additional $20-30 \%$ input (summated at a slower rate) to initiate cell firing.

AP-initiation site expands along the axon during spiking. The AP axon initiation site was reported to be within $\sim 20 \mu \mathrm{m}$ from the granule cell soma in rats (whole-cell recordings from axonal blebs $)^{31}$ and in mice (loose-patch axonal recordings) ${ }^{32}$. To determine its location in our experiments, we carried out dualpatch recordings from the soma (whole-cell) and the axon (loose patch) of granule cells (Fig. 2a), as detailed previously ${ }^{25}$. In these settings, somatic and axonal events could be readily identified and analysed (Fig. 2b,c). The AP-initiation site was determined by documenting the time lag, or latency $\left(t_{\mathrm{a}}-t_{\mathrm{s}}\right)$ between the axonal spike (latency $t_{\mathrm{a}}$ ) recorded at different distances from the soma, and the somatic spike (latency $t_{\mathrm{s}}$; Fig. $2 \mathrm{~b}-\mathrm{d}$; Methods). We found that the $\left(t_{\mathrm{a}}-t_{\mathrm{s}}\right)$ value reached its minimum when the axonal electrode was $20-25 \mu \mathrm{m}$ from the soma (Fig. 2d), thus indicating the AP-initiation site ${ }^{33}$ consistent with previous observations ${ }^{31,32}$. We also found that spikes could propagate along MFs with high fidelity ( $>99.5 \%$ at the highest possible spiking frequency due to somatic depolarization), although a moderate increase in extracellular $\mathrm{K}^{+}$(to $5 \mathrm{mM}$, compatible with conditions of epileptiform activity) could prompt significant propagation failures (Supplementary Fig. 1).

Under baseline conditions, we also compared $\left(t_{\mathrm{a}}-t_{\mathrm{s}}\right)$ values for the first and the subsequent spikes during 200-ms depolarization. By the third consecutive AP, the minimal $\left(t_{\mathrm{a}}-t_{\mathrm{s}}\right)$ values became spread over a 100 - to $120-\mu \mathrm{m}$-long axonal segment, in sharp contrast with the highly localized site for the first spike (Fig. 2e, black and green dots). This spread was quantitatively reflected in the negative regression, within the proximal axonal segment $(0-200 \mu \mathrm{m})$, between the use-dependent change in $\left(t_{\mathrm{a}}-t_{\mathrm{s}}\right)$ and the distance from the soma $(n=43$, $P<0.006$ at $25^{\circ} \mathrm{C}$, and $n=17, P<0.002$ at $33^{\circ} \mathrm{C}$; Student's $t$-test for regression slope; Fig. 2f,g); at the same time, $\left(t_{\mathrm{a}}-t_{\mathrm{s}}\right)$ values remained negative over the longer distances (at $P<0.001$ for distance $>250 \mu \mathrm{m}$, one-sample $t$-test). The initial negative slope along with the negative value of distant data in the scatter were consistent with the spike-initiation site expansion predicted by straightforward Monte Carlo tests of (Fig. 2h, Supplementary Fig. $2 \mathrm{a}-\mathrm{c})$. However, the fact that $\left(t_{\mathrm{a}}-t_{\mathrm{s}}\right)$ values partly returned closer to zero values at $>200 \mu \mathrm{m}$ also suggested a contribution of activity-dependent spike deceleration in proximal segments ${ }^{32}$ (Supplementary Fig. 2d-f). The overall effect appeared to reach 
a
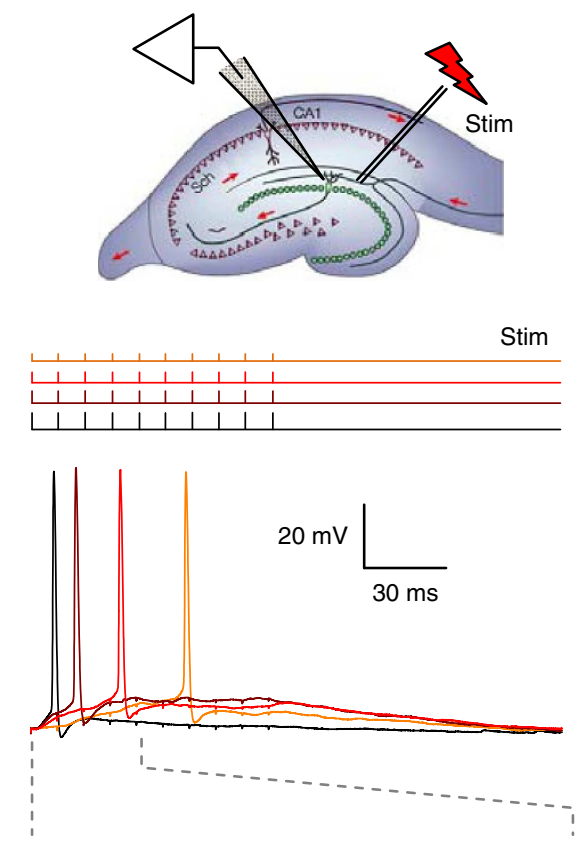

b

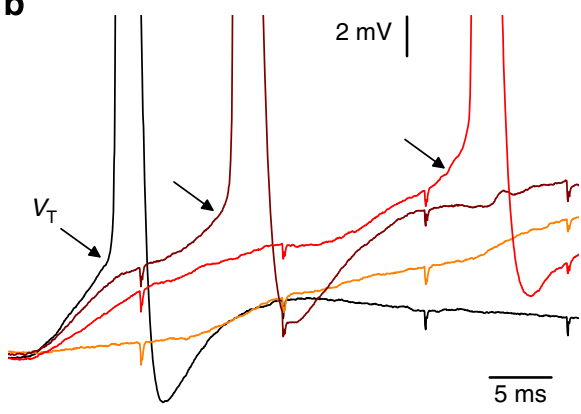

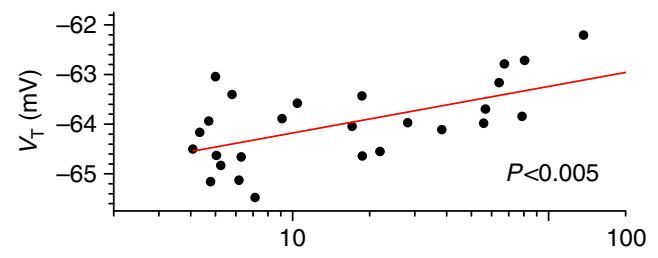
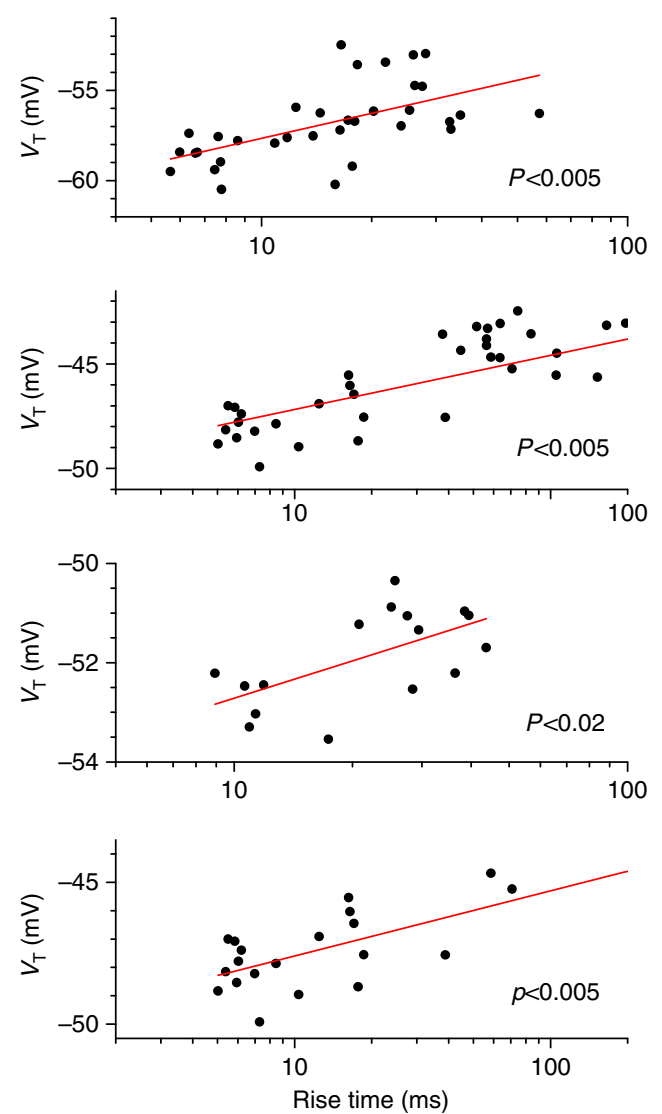

Figure 1 | Synaptic input modulates the spiking threshold of dentate granule cells. (a) Inset: experiment diagram. Upper traces: pattern of electric stimuli applied with varied amplitudes to the presynaptic perforant fibres, as depicted. Lower traces: the corresponding somatic voltage recordings (colour-coded accordingly) show a characteristic one-cell example. (b) Somatic voltage traces in a expanded as shown by dashed lines; arrows depict spiking threshold values $\left(V_{T}\right)$ that visibly increase with lower rates of perforant fibre excitation-induced somatic depolarization. (c) Multiple trials recorded, in an arbitrary sequence, in five individual cells show strong correlation between the rate of depolarization (set by the synaptic input strength) and the granule cell-spiking threshold $\left(V_{T}\right)$. Experiments carried out at $33^{\circ} \mathrm{C}$.

its peak by the third spike (30-50 ms after the depolarization onset, Supplementary Fig. 3).

Importantly, by the third spike the average variability of the $\left(t_{\mathrm{a}}-t_{\mathrm{s}}\right)$ values among cells increased considerably (compare the vertical scatter of black and green dots in Fig. 2e). This was a direct consequence of increased trial-to-trial $\left(t_{\mathrm{a}}-t_{\mathrm{s}}\right)$ variability in individual axons: the s.d. of measured $\left(t_{\mathrm{a}}-t_{\mathrm{s}}\right)$ values increased from $60 \pm 10 \mu \mathrm{s}$ for the first spike to $180 \pm 35 \mu$ s for the third spike at $25^{\circ} \mathrm{C}$ (measured in $n=14$ cells, $P<0.006$; $t$-test here and thereafter) and from $47 \pm 13$ to $82 \pm 19 \mu$ s at $33^{\circ} \mathrm{C}(n=9$, $P<0.005)$. Such two- to threefold increases in the variability could not be explained by an increased latency measurement error by the third spike (its amplitude decreased by only $20-30 \%$ ) but most likely reflected the uncertainty, or the stochastic nature, of the AP-initiation point along an expanded segment of the proximal axon. Clearly, the increased variability of $\left(t_{\mathrm{a}}-t_{\mathrm{s}}\right)$ values could also be partly due to use-dependent deceleration of local spikes. In summary, these data suggest that somatic excitation resulted in the probability of spike initiation distributed more evenly along the proximal axonal segment, compared with the resting conditions.

AP-initiation site expands during subthreshold excitation. We next asked whether somatic depolarization directly controlled by somatic current injection can also affect the AP-initiation region. We therefore compared $\left(t_{\mathrm{a}}-t_{\mathrm{s}}\right)$ values for the APs generated following either shorter $(0-15 \mathrm{~ms})$ or longer $(15-120 \mathrm{~ms})$ intervals of subthreshold depolarization, in the same cell (Fig. 3a). The depolarization rate was controlled by the amplitude of the current injection step applied through a somatic pipette (current-clamp mode): due to the capacitive and active-conductance properties of granule cells, step injection produces gradual depolarization (Fig. 3a). We have found that slowing down the depolarization rate reduced the $\left(t_{\mathrm{a}}-t_{\mathrm{s}}\right)$ value progressively with greater distances from the soma (Fig. $3 \mathrm{~b} ; P<0.005, n=11$ at $25^{\circ} \mathrm{C}$; $P<0.013, n=12$ at $\left.33^{\circ} \mathrm{C}\right)$, similar to the effect observed during repetitive spiking (compare with data in Fig. 2f,g). 
a

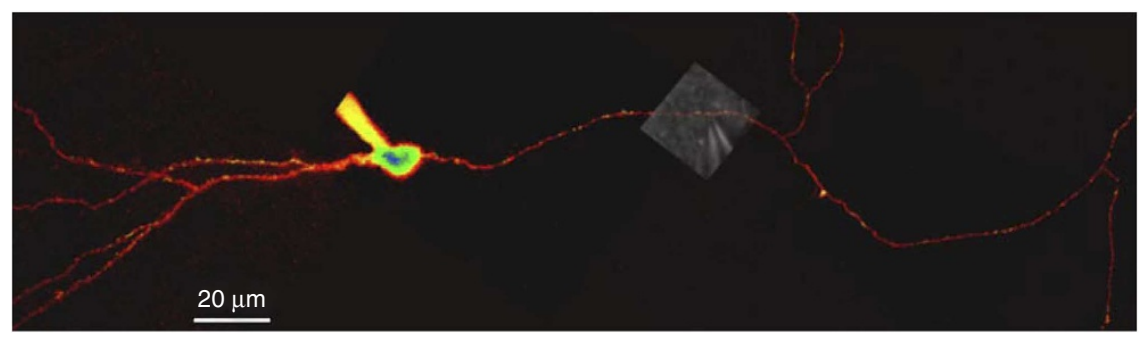

b
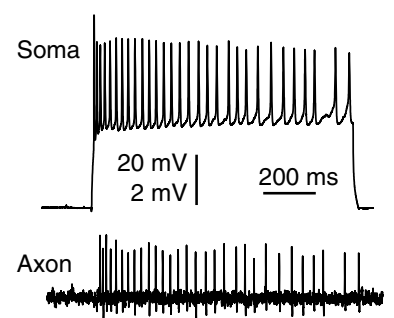

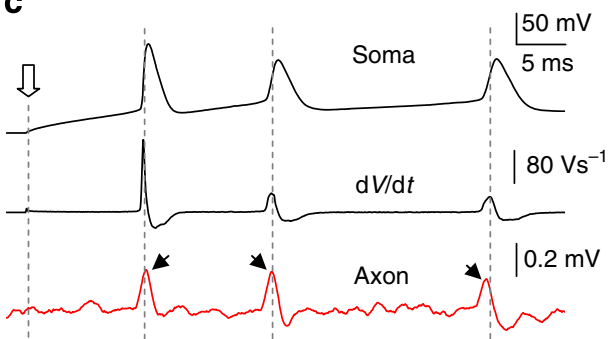

d

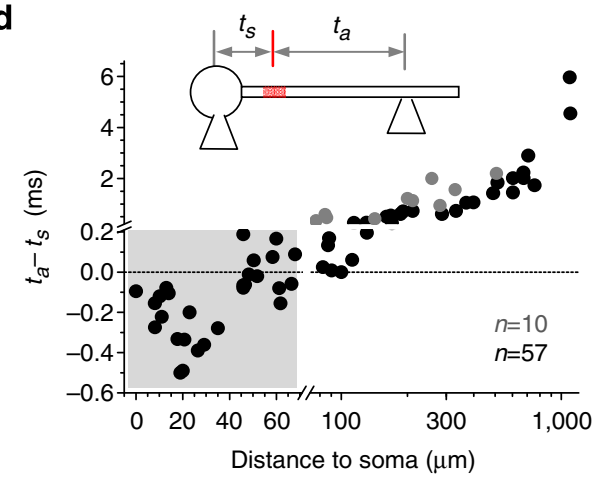

f

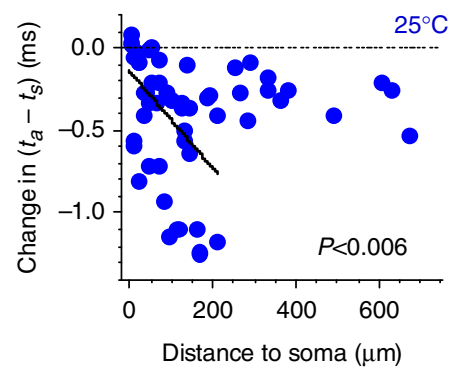

g

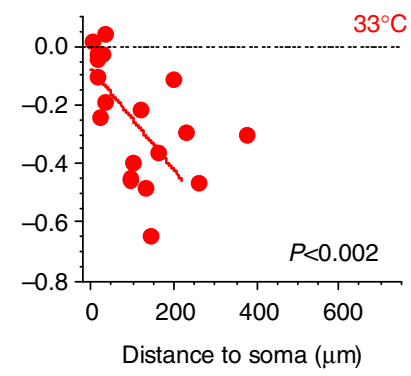

e

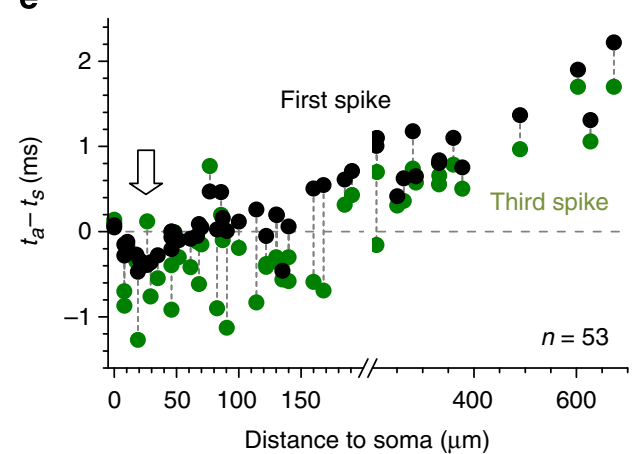

h

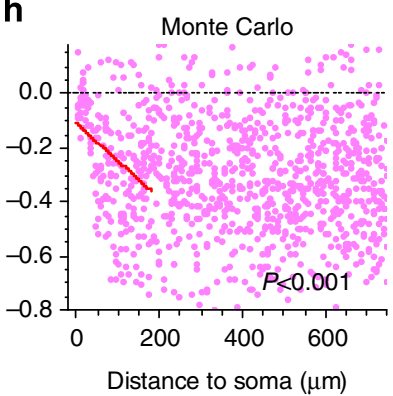

Figure 2 | The axonal spike-initiation area broadens away from the soma during somatic excitation. (a) Typical experiment: granule cell held in whole-cell mode $\left(40 \mu \mathrm{M}\right.$ Alexa Fluor $594, \lambda_{x}^{2 P}=800 \mathrm{~nm}$ ), with an axonal bouton loose-patched (DIC inset overlay). (b) Characteristic spikes at the soma (upper trace) and in the axon (lower trace, loose patch; voltage scales apply accordingly) upon a depolarizing pulse; current clamp. (c) Example as in b on a magnified timescale; traces, somatic $V_{\mathrm{m}}$ including three spikes (top), $\mathrm{dV} / \mathrm{d} t$ (middle), and axonal spikes recorded at $\sim 100 \mu \mathrm{m}$ from the soma (bottom). Dotted lines, somatic spike onset ( $\mathrm{d} V / \mathrm{d} t$ peak); arrows, axonal spike peaks (indicating a shift towards an earlier onset for the third axonal spike relative to somatic AP). (d) The $\left(t_{\mathrm{a}}-t_{\mathrm{s}}\right)$ latency values for somatic $\left(t_{\mathrm{s}}\right)$ and axonal $\left(t_{\mathrm{a}}\right)$ spikes versus pipette position in the axon (inset). Black and grey dots, data recorded in individual axons from the main branch $(n=57$ pairs $)$ and collaterals $(n=10)$, respectively. Grey shade, proximal axonal segment on an expanded scale; the AP-initiation site is near the minimal $\left(t_{\mathrm{a}}-t_{\mathrm{s}}\right)$ value $\left(20-25 \mu \mathrm{m}\right.$ from the soma). (e) $\left(t_{\mathrm{a}}-t_{\mathrm{s}}\right)$ values for the first (black) and the third (green) spikes invoked by somatic depolarization as in $\mathbf{b}$; spikes from the same train are connected by dotted lines ( $n=53$ soma-axon pairs). Arrows, the approximate position of the AP-initiation site in baseline conditions (first spike). (f,g) The $\left(t_{\mathrm{a}}-t_{\mathrm{s}}\right)$ latency change by the third spike (at 25 and $33^{\circ} \mathrm{C}$, as indicated) is negatively correlated with the axonal distance in the proximal $(0-200 \mu \mathrm{m})$ segment; lines, linear regression; $n=53$ cells at $25^{\circ} \mathrm{C}$, and $n=17$ at $33^{\circ} \mathrm{C}$. (h) Monte Carlo simulations (example) mimicking an expansion of the AP-initiation site by the third spike predicting negative correlation between the $\left(t_{\mathrm{a}}-t_{\mathrm{s}}\right)$ latency change and the axonal distance, within the proximal segment as in $(\mathbf{f}, \mathbf{g})$; line, linear regression $(P<0.001) ; 1,000$ points simulated, see Supplementary Fig. 2 for detail.

Somatic influence on the $\mathrm{Na}^{+}$channels weakens with distance. The most parsimonious explanation for the use-dependent expansion of the AP-initiation site is that during somatic depolarization the peak density of available $\mathrm{Na}^{+}$channels shifts away from the soma. A basic physiological mechanism that could account for this is partial inactivation of axonal $\mathrm{Na}^{+}$channels 
a

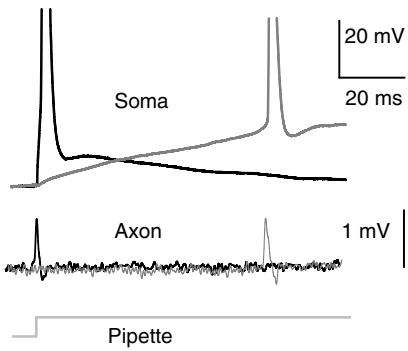

b

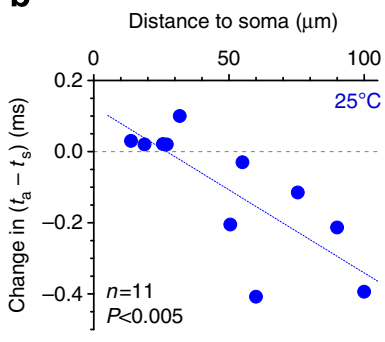

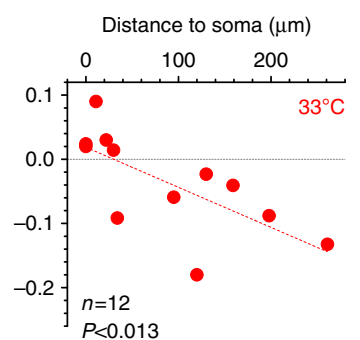

C
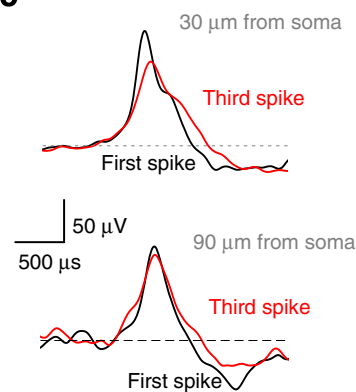

c

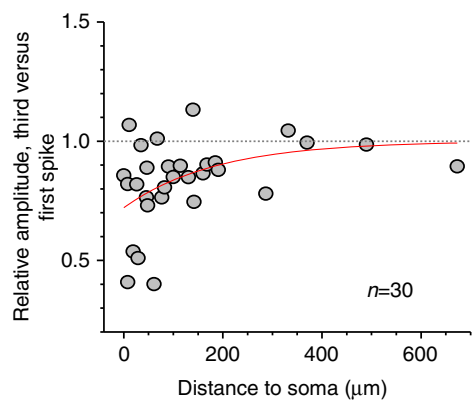

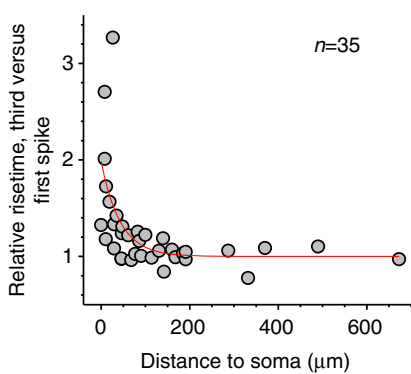

Figure 3 | Depolarization broadens the spike-initiation area slowing down local spikes. (a) Characteristic recordings of somatic (upper trace) and axonal (lower trace, $\sim 75 \mu \mathrm{m}$ from the soma) spikes generated following shorter (black) and longer (grey) subthreshold depolarization periods, as indicated. (b) A summary of changes in the $\left(t_{\mathrm{a}}-t_{\mathrm{s}}\right)$ latency plotted for different recording positions in the axon (compare with Fig. 2f). Dashed lines, linear regression $\left(n=11\right.$ at $25^{\circ} \mathrm{C}, P<0.005 ; n=12$ at $33^{\circ} \mathrm{C}, P<0.013$ ) suggesting an increase in the expected distance between the axonal AP-initiation site and the soma. (c) Characteristic examples of axonal recordings showing the first (black) and third (red) spikes generated during somatic depolarization (as in Fig. 2c) for a relatively proximal (top) and a relatively distal (bottom) axonal recording site, as indicated. (d) Changes in the amplitude (left panel, $n=30$ ) and the rise time (right panel, $n=35$ ) of the third compared with the first spike, plotted against the distance from the recording site to the soma. Red lines, best fit single-exponential decay.

because of depolarization propagating into the axon. Two earlier observations support this hypothesis. First, in hippocampal MFs the recovery of $\mathrm{Na}^{+}$channels from depolarization-dependent inactivation could last for seconds ${ }^{34}$ even though their post-spike inactivation recovery is relatively rapid, $10-20 \mathrm{~ms}^{35}$. More recently, outside-out patch recordings from axonal patches provided direct characterization of the $\mathrm{Na}^{+}$channel kinetics and its depolarization-dependent inactivation in $\mathrm{MFs}^{29}$. Second, depolarization of granule cells readily propagates into the axon showing a distance-dependent decay ${ }^{25,27}$. We therefore asked whether we could detect changes in the local axonal spike waveform that would depend on somatic depolarization and the distance from the soma. To achieve this, we compared the waveforms of the first and the third axonal spikes generated by somatic depolarization in the same current trace (Fig. 3c).

As loose-patch axonal recordings represent a mixture of membrane voltage $V(\mathrm{t})$ and, predominantly, its first derivative $\mathrm{d} V(t) / \mathrm{d} t^{36,37}$, we considered both amplitudes and rise times of recorded deflections. We found that near the soma the spike amplitude was robustly reduced by the time of the third AP (by $28 \pm 6 \%$ ) and that this reduction decayed with a length constant of $187 \pm 108 \mu \mathrm{m}$ along the axon (mono-exponential fit; $n=30$ soma-axon pairs; Fig. 3d, left). Similarly, by the third AP the spike rise time was increased by $98 \pm 23 \%$ (that is, by $150-200 \mu \mathrm{s}$ ) near the soma, and this deceleration effect decayed along the axon with a length constant of $43 \pm 18 \mu \mathrm{m}$ ( $n=35$; Fig. $3 \mathrm{~d}$, right). Whether the recorded axonal spikes represent $V(t)$ or $\mathrm{d} V(t) / \mathrm{d} t$, or both, these data clearly indicate that somatic excitation reduces the speed with which axonal $V(t)$ rises during spike generation and that this effect fades away with distance along the axon.
The AP waveform is dictated by the interplay between ion currents through $\mathrm{Na}^{+}$and $\mathrm{K}^{+}$channels. Recent analyses of spiking mechanisms in MFs have indicated that the onset of the $\mathrm{K}^{+}$current is close to the end of the $\mathrm{Na}^{+}$current transient ${ }^{29,38}$. Therefore, the changes in the AP rising phase documented here (Fig. 3c,d) should reflect a decrease in $\mathrm{Na}^{+}$channel activation, which is weakening with greater distances from the soma. This phenomenon is likely to reflect a simple (but not demonstrated previously) mechanism by which somatic depolarization partially inactivates axonal $\mathrm{Na}^{+}$channels in a distance-dependent manner. This is because depolarization-dependent inactivation of $\mathrm{K}^{+}$channels should, if anything, affect the decay, rather than rise time, of the $\mathrm{AP}^{28,29,38,39}$.

Somatic depolarization shifts away peak axonal $\mathrm{Na}^{+}$entry. The expression of $\mathrm{Na}^{+}$channel subunits peaks within the MF axon initial segment coincident with the AP-initiation site ${ }^{32}$. To test whether this reflects the distribution of AP-evoked $\mathrm{Na}^{+}$ entry along the axon, we imaged axonal $\mathrm{Na}^{+}$entry using the $\mathrm{Na}^{+}$-sensitive fluorophore SBFI $\left(K_{\mathrm{D}} \sim 25 \mathrm{mM}\right)^{40}$. As the lowaffinity SBFI imposes heavy time filtering and yields a relatively low signal-to-noise ratio for individual spike-evoked $\mathrm{Na}^{+}$signals, we evoked five spikes at $20 \mathrm{~Hz}$ using 2 -ms depolarizing pulses while monitoring SBFI fluorescence along the axon (Fig. 4a,b). In these experiments, the $\mathrm{Na}^{+}$-dependent inverse fluorescence increment indeed peaked $20-25 \mu \mathrm{m}$ from the soma (Fig. 4c, $n=60$ recorded sites), consistent with the AP-initiation site (Fig. 2d). An explicit kinetic model of $\mathrm{Na}^{+}$entry, together with an independent estimate of the SBFI association constant $\left(k_{\mathrm{on}} \sim 2.0 \mathrm{M}^{-1} \mathrm{~ms}^{-1}\right)$, suggested that these data correspond to 
a

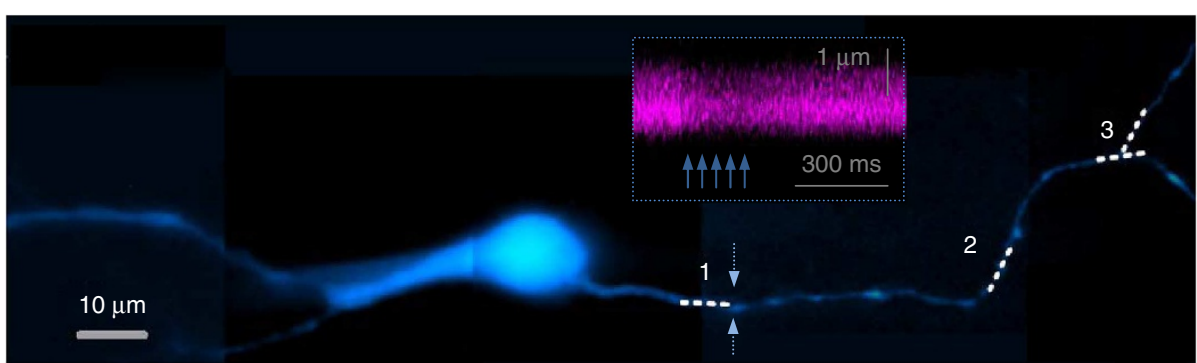

b

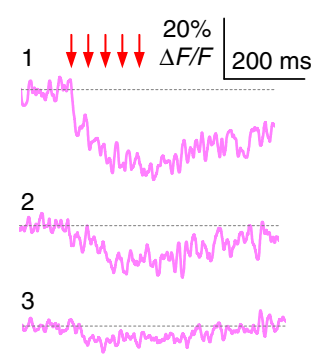

C

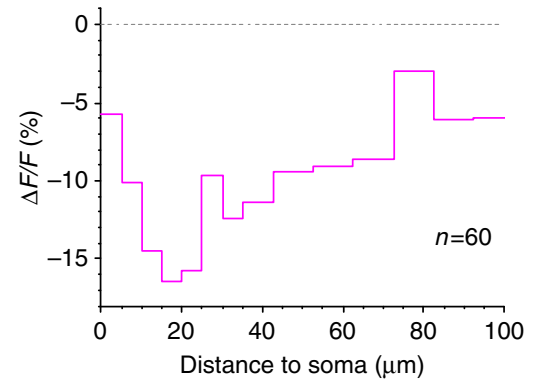

d

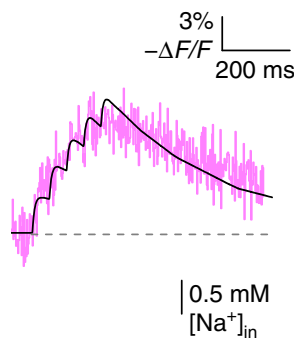

e

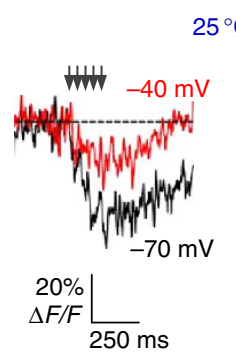

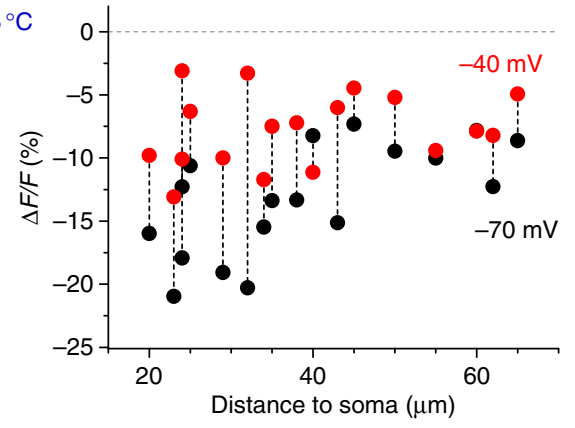

f

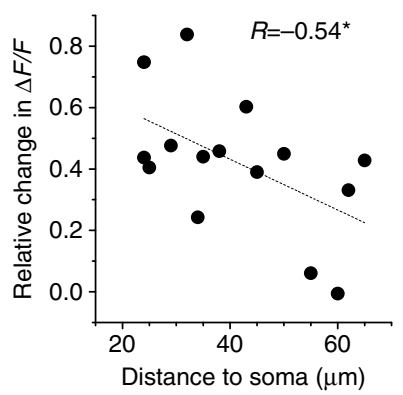

g

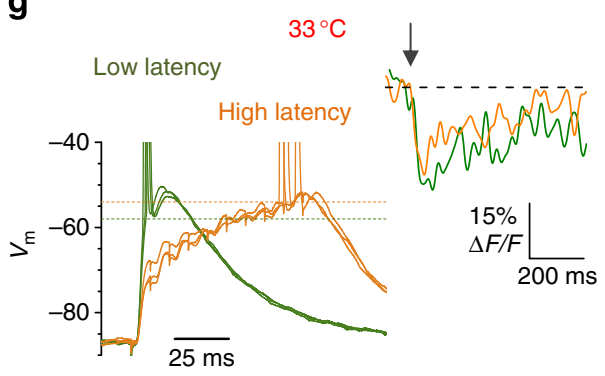

h

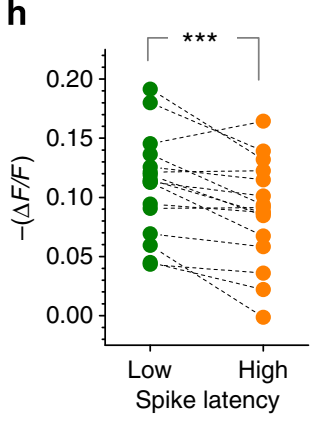

i

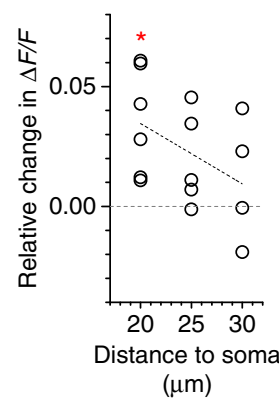

Figure 4 | Somatic depolarization flattens the profile of $\mathbf{N a}^{+}$entry along the axon. (a) Image: granule cell filled with $1 \mathrm{mM} \mathrm{SBFI} \mathrm{(for} \mathrm{example,} \mathrm{collage} \mathrm{of}$ averaged 20-30 $\mu \mathrm{m}$ z-stacks, $\lambda_{x}^{2 P}=800 \mathrm{~nm}$ ); dotted segments 1-3, recording sites; inset, example linescan at site 1 (dotted arrows, scan position).

(b) Characteristic linescan traces in response to five APs at $20 \mathrm{~Hz}$ as shown in a. (c) Axonal distribution of relative $\Delta F / F$ amplitude (evoked by five APs at $20 \mathrm{~Hz}$ ). To improve $\mathrm{S} / \mathrm{N}$ ratio, two largest $\Delta F / F$ (out of 3-10 traces) within each bin were averaged $(n=60$ recorded sites in total). (d) Average $S B F I \Delta F / F$ signal (magenta, top scale) near the spike-initiation segment (as in $\mathbf{a}, \mathbf{b}$ ), and the best-fit model representation (black, bottom scale) of $\mathrm{Na}^{+}$entry; see details in Methods and Supplementary Fig. 4. (e) Traces: SBFI fluorescence (example) in proximal axon evoked by five spikes at $20 \mathrm{~Hz}$ (as in a) under baseline conditions (black, $-70 \mathrm{mV}$ ) and during somatic pre-depolarization (to $-40 \mathrm{mV}$; red). Plot: summary, the SBFI $\Delta F / F$ amplitude versus distance from the soma (data at $>20 \mu \mathrm{m}$ shown to reduce bias due to somatic $\mathrm{Na}^{+}$diffusion sink); $25^{\circ} \mathrm{C}$. (f) Relative changes in $\Delta F / F$ from experiments in $\mathbf{e}$; line, negative linear regression $(n=15$, Pearson's $R=-0.54, P<0.04)$. (g) Left traces: somatic voltage during electrical stimulation of presynaptic perforant path fibres (as in Fig. 1) with stronger (green) and weaker (orange) stimuli; dotted lines, higher spiking threshold upon slower depolarization. Right traces: $\mathrm{SBFI} \triangle F / F$ recorded simultaneously in the proximal axon (colour-coded accordingly); $33^{\circ} \mathrm{C}$. (h) Summary of experiments shown in $\mathbf{g}$ : colour-coded accordingly; ${ }^{\star \star \star} P<0.002, n=16$ cells. (i) Summary of experiments shown in $\mathbf{g}$ : increases in AP-evoked $\mathrm{Na}^{+}$entry SBFI $\Delta F / F$ amplitude) due to reduced spike latency (faster depolarization) are weaker with greater distances from soma; data average at $20 \mu \mathrm{m}$ are significantly above zero $\left({ }^{\star} P<0.02, n=6\right.$, t-test); dotted line, best-fit linear slope. 
an $~ 0.4-\mathrm{mM}$ increment of axonal $\mathrm{Na}^{+}$per spike near the APinitiation site (Fig. 4d; Supplementary Fig. 4). If the depolarization- and distance-dependent inactivation of $\mathrm{Na}^{+}$ channels indeed underlies the expansion of the AP-initiation site, then the profile of $\mathrm{Na}^{+}$entry along the axon should change correspondingly. As existing $\mathrm{Na}^{+}$imaging techniques cannot directly measure $\mathrm{Na}^{+}$entry on the submillisecond scale (for spike latency readout), we tested our hypothesis in two alternative types of experiments.

In the first experiment, we used relatively crude somatic voltage manipulation. We monitored axonal $\mathrm{Na}^{+}$entry evoked by a brief train of spikes, with and without the granule cell soma depolarized to $-40 \mathrm{mV}$ before the spike onset. We found that depolarization markedly reduced the AP-evoked $\mathrm{Na}^{+}$entry in recorded sites within $\sim 70 \mu \mathrm{m}$ from the soma (Fig. $4 \mathrm{e}$ ), suggesting overall reduction in $\mathrm{Na}^{+}$channel activation. Importantly, this reduction was consistently weaker with greater distances from the soma (Fig. 4f) reflecting a decaying effect on $\mathrm{Na}^{+}$channels and the flattening of $\mathrm{Na}^{+}$entry along the axon (Fig. 4e, red dots). As these experiments provided only a first-approximation assessment of the physiological scenario in question, in the second experiment we reproduced the protocol depicted in Fig. 1 (at $33^{\circ} \mathrm{C}$ ) in which the cell-spiking threshold was regulated by the variable synaptic input-induced depolarization. Simultaneously, we imaged $\mathrm{Na}^{+}$entry in the proximal axonal segment, $20-40 \mu \mathrm{m}$ from the soma (Fig. 4g; Supplementary Fig. 5). The results showed clearly that slowing down the excitatory input (hence elevating the spike threshold) significantly reduced axonal $\mathrm{Na}^{2+}$ entry (by $24 \pm 7 \%, n=16, P<0.002$; Fig. 4 h), with the effect decaying with greater distances from the soma (Fig. 4i). Taken together, $\mathrm{Na}^{+}$imaging tests thus lent support to our hypothesis suggesting the distance-dependent inactivation of axonal $\mathrm{Na}^{+}$ channels upon somatic excitation as a mechanism for the expansion of the spike-initiation site.

Changes in axonal $\mathrm{Ca}^{2+}$ entry point to $\mathrm{Na}^{+}$channel inactivation. To further assess the roles of $\mathrm{Na}^{+}$and $\mathrm{K}^{+}$channels in use-dependent changes of axonal spiking, we set out to monitor axonal $\mathrm{Ca}^{2+}$ entry. This approach has a simple rationale. As $\mathrm{Ca}^{2+}$ channels themselves undergo little or no inactivation in conditions of our experiments, axonal $\mathrm{Ca}^{2+}$ entry depends almost entirely on the kinetics of $\mathrm{Na}^{+}$and $\mathrm{K}^{+}$channels that shape the AP: partial inactivation of $\mathrm{Na}^{+}$channels should either have little effect or decrease $\mathrm{Ca}^{2+}$ entry, whereas partial inactivation of $\mathrm{K}^{+}$channels should increase $\mathrm{Ca}^{2+}$ entry due to the spike-broadening ${ }^{28,39}$. Thus, if $\mathrm{K}^{+}$channel inactivation dominated during somatic depolarization, we should observe an increase in $\mathrm{Ca}^{2+}$ entry as depolarization progresses, with such an increase being the greatest near the soma (where depolarization is at its strongest).

We therefore loaded granule cells with a $\mathrm{Ca}^{2+}$ indicator $(200 \mu \mathrm{M}$ Fluo-4; Fig. 5a) and carried out two complementing experiments. In the first experiment, we evoked brief trains of spikes by injecting a subthreshold depolarizing current superimposed with $1-\mathrm{ms}$ pulses (at $20 \mathrm{~Hz}$, current clamp; Fig. 5b,c). a

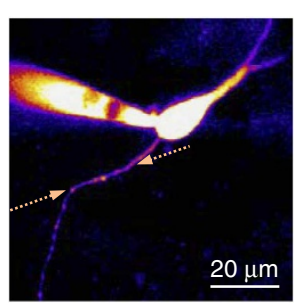

b

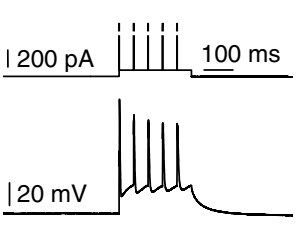

C

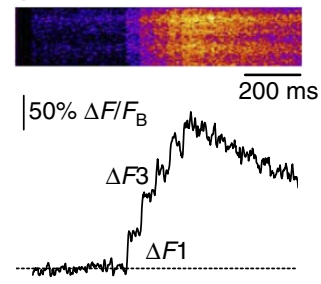

d

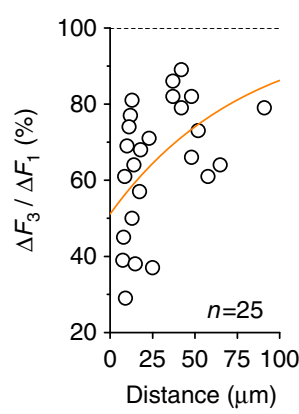

e

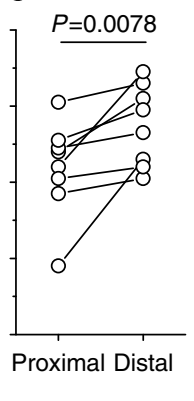

f
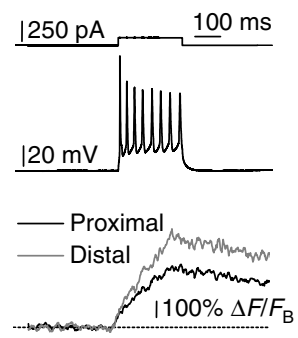

9

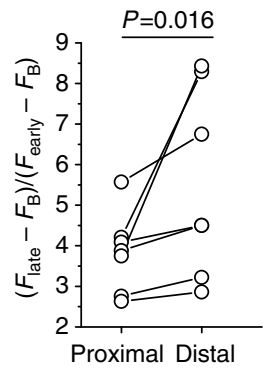

Figure 5 | Somatic excitation inhibits axonal $\mathbf{C a}^{2+}$ entry preferentially in proximal segments. (a) A typical fluorescence image of a dentate gyrus granule cell (Alexa Fluor 594, $\lambda_{x}^{2 P}=800 \mathrm{~nm}$ ) with a proximal axonal fragment imaged in linescan mode (dotted arrows, linescan position). (b) A 250-ms depolarizing current superimposed with current pulses $(0.5-1 \mathrm{~ms}, 1-2 \mathrm{nA}, 20 \mathrm{~Hz}$; top trace) induces a burst of regular spikes (bottom trace).

(c) Characteristic $\mathrm{Ca}^{2}+$ transients recorded in an experiment shown in $\mathbf{a}, \mathbf{b}$; eight trial average; top, original linescan; bottom, quantified trace. $\Delta F_{1}$ and $\Delta F_{3}$ denote $\mathrm{Ca}^{2+}$-dependent fluorescence increments evoked by the first and the third spikes, respectively. (d,e) The ratio $\Delta F_{3} / \Delta F_{1}$ is lowest near the soma and increases progressively with the distance along the axon $(\mathbf{d} ; n=25$, orange line: exponential fit). In eight cases (e), recordings were made from proximal and distal sites on the same axon allowing direct paired-sample comparison (Wilcoxon signed-rank test; in this sample, the average distance to the proximal site was $38.9 \pm 5.9 \mu \mathrm{m}$ and between proximal and distant sites was $14.9 \pm 1.6 \mu \mathrm{m})$. Throughout the sample, $\Delta F_{1} / F_{\mathrm{B}}\left(F_{\mathrm{B}}\right.$ stands for baseline fluorescence) showed no correlation with the distance from the soma (Spearman rank test $P=0.556, n=25$ ). (f) An example of cell spiking evoked by a depolarizing current (upper trace) and the average $\mathrm{Ca}^{2}+$ fluorescence responses in proximal and distal axonal sites (lower trace, $n=7$ ); note that the spike-evoked fluorescence increments are smoothed out in the average trace because of the jitter in spike timing. (g) A summary of experiments shown in $\mathbf{f}$; the average distance from the soma to the proximal site was $32.4 \pm 12.8 \mu \mathrm{m}$ and the distance between proximal and distant sites was $10.7 \pm 1.4 \mu \mathrm{m}$ (mean \pm s.e.m.). $F_{\mathrm{B}}, F_{\text {early }}$ and $F_{\text {late }}$ denote, respectively, baseline $\mathrm{Ca}^{2}+$ fluorescence and the fluorescence signal integrated over $0-40$ and 40-200 ms post onset. In these recordings, $F_{B}$ showed no distance dependence ( $P=0.69, n=7$, Wilcoxon signed-rank test). 
This protocol provided time-locked APs across the experiments, also enabling us to compare spike-evoked $\mathrm{Ca}^{2+}$ entry at different points along the axon. Previously, we showed that in these conditions the increment of Fluo- 4 fluorescence $\Delta F$ evoked by a spike gives a robust indicator of $\mathrm{Ca}^{2+}$ entry ${ }^{41}$. In these experiments, the ratio between $\Delta F$ increments during the third and the first spikes $\left(\Delta F_{3} / \Delta F_{1}\right)$ was lowest near the soma while increasing substantially with more distal recording sites, be the data analysed as one sample (Fig. 5d) or compared in one-axon pairs (Fig. 5e). A qualitatively identical conclusion was obtained in the complementing experiment in which the soma was progressively depolarized to generate a brief train of spikes (with some expected spike onset jitter), with $\mathrm{Ca}^{2+}$ monitored at two axonal sites (Fig. 5f,g). We also confirmed that our $\mathrm{Ca}^{2+}$ data could not be explained by the distance-dependent $\mathrm{Ca}^{2+}$ indicator saturation because $\mathrm{Ca}^{2+}$ entry $(\Delta F)$ did not correlate with the distance to the soma over the measured intervals $(P=0.556$, $n=25$, Spearman rank test), unlike in some other central neurons ${ }^{42}$. Our observations were thus diametrically opposite to those expected if inactivation of $\mathrm{K}^{+}$channels was to play a dominant role here (see above). By exclusion, we were left with the only plausible explanation for our findings: somatic excitation partly inactivated axonal $\mathrm{Na}^{+}$channels, in a distance-dependent manner.

Biophysics predicts expansion of the spike-initiation site. To test whether partial $\mathrm{Na}^{+}$channel inactivation in proximal axonal segments due to somatic depolarization could provide a selfsufficient mechanistic explanation for our observations, we used a detailed NEURON model of a morphologically reconstructed dentate granule cell ${ }^{31}$. In this model, the dendritic electric properties were exhaustively tested ${ }^{31}$, and the basic axon parameters were evaluated in our earlier dual-patch study ${ }^{25}$ (Methods). As we aimed to understand the mechanism in principle, we focused on the distribution of $\mathrm{Na}^{+}$and $\mathrm{K}^{+}$ channel conductance only, in correspondence with our imaging data and the immunofluorescence results reported earlier ${ }^{32}$ (Methods, Supplementary Fig. 6a,b). In granule cells, axonal and somatic $\mathrm{Na}^{+}$channels differ in their inactivation properties $^{35}$, and therefore both channel types ${ }^{31,35}$ were incorporated correspondingly in our model (Supplementary Fig. 6a,b). APs elicited in this model could be seen to be initiated in the proximal axon (Fig. 6a), in good agreement with our experimental observations.

Simulations predicted that the depolarization-dependent inactivation of $\mathrm{Na}^{+}$channels could indeed alter AP generation in the axon. As cell spiking progresses, APs begin to initiate over a wide axonal region, rather than within a narrow proximal site (note relatively shallow and expanded false-colour gradients in proximal axonal segments in Fig. $6 \mathrm{~b}$ compared with Fig. 6a; for the sake of clarity, no stochastic component mimicking experimental observations of spike initiation was included). In the same model, injecting a train of modelled synaptic currents of varying intensity in the soma produced adaptive changes in the cellspiking threshold (lower threshold with steeper excitation; Fig. 6d), which were fully consistent with our experimental observations (Fig. 1). Equipping the model with the recently updated MF Na ${ }^{+}$channel kinetics ${ }^{29}$ produced a similar outcome indicating a robust nature of this phenomenon (Supplementary Fig. 6c). Correspondingly, subthreshold depolarization prominently inactivated $\mathrm{Na}^{+}$channels resulting in a substantial latency shift (orange line, Fig. 6e).

This was consistent with the spike-initiation site expanding along the axon, away from the soma. To confirm that the effect was not a spurious consequence of post-spike relaxation phenomena in the model, we forced spike trains without depolarization (by generating $0.5-\mathrm{ms}$ pulses at resting voltage). Spiking without depolarization resulted in little $\mathrm{Na}^{+}$channel inactivation during the train, no latency changes between the first and third consecutive spikes, and hence no changes in the spikeinitiation site (green line in Fig. 6e). Next, we introduced voltagegated $\mathrm{Ca}^{2+}$ channels in the model (generic VGCCs adapted from the study by Royeck et al. ${ }^{43}$ ). This prompted the model to reproduce not only the recorded progressively decreasing $\mathrm{Ca}^{2+}$ entry near the soma during depolarization-induced spiking (Fig. 6f) but also the weakening of this effect with greater distances from the soma (Fig. 6g), in accord with our experimental observations (Fig. 5). Finally, an artificial increase in depolarization-dependent $\mathrm{K}^{+}$channel inactivation in the model predicted changes in use-dependent $\mathrm{Ca}^{2+}$ entry (Supplementary Fig. 7), which were opposite to what we recorded (Fig. 5), thus again confirming the predominant role of $\mathrm{Na}^{+}$channel inactivation. Taken together, our simulations with the realistic granule cell model, complemented by Monte Carlo tests dealing with a stochastic component of spike initiation (Fig. 2h, Supplementary Fig. 2), could thus reproduce and mechanistically explain our experimental observations made throughout the study.

\section{Discussion}

The main findings of this study are as follows. First, we showed that hippocampal granule cells, similar to many other neurons in the CNS, can adapt their spiking threshold to the rate of the excitatory glutamatergic input (enacted by perforant path synapses). The extent of this adaptation is significant: slowing down the synaptic input could have the same effect on cell firing as $20-30 \%$ of the total presynaptic input. Consequently, stronger synchronization of perforant path inputs is likely to have an advantage in terms of firing the cell compared with less synchronized inputs that produce the same cumulative excitation. The adjustment of cell excitability to physiological activity thus occurs in real time, on the scale of dozens of milliseconds. To understand the underlying mechanism, we asked how the somatic depolarization affects spike initiation in the initial axonal segment. It was recently reported that even small plastic changes in the availability or distribution of $\mathrm{Na}^{+}$channels in this segment may have a profound effect on cell excitation ${ }^{16,21}$.

We found that, under resting conditions, the MF spikeinitiation site was $20-25 \mu \mathrm{m}$ from the soma, consistent with earlier observations ${ }^{31,32}$, whereas APs propagated reliably along the MFs, up to the maximal firing frequency. The latter finding suggests that use-dependent short-term plasticity of MF transmission $^{24,44}$ is unlikely to involve AP propagation failures, at least under baseline conditions. More importantly, during somatic excitation, the area of AP initiation broadens dramatically along the axon. This broadening is paralleled by the reduction in the rate of voltage rise, and consequently in the apparent propagation speed, of local axonal spikes: the effect was greatest in most proximal axonal segments and faded away at larger distances from the soma. In theory, having a broad AP-initiation site could be interpreted as APs starting to generate 'quasisimultaneously' over a relatively large axonal region. A more realistic scenario, however, is that individual APs are initiated stochastically at various sites along the initiated region. Indeed, stochastic AP generation is expected to increase the variability for soma-axon spike latencies, which is fully consistent with our data indicating that the trial-to-trial variability of $\left(t_{\mathrm{a}}-t_{\mathrm{s}}\right)$ increases during the spike train (also reflected in the increased variability across the sample and suggestive of local spike slowdown). This observation proposes that the probability of AP initiation 
a

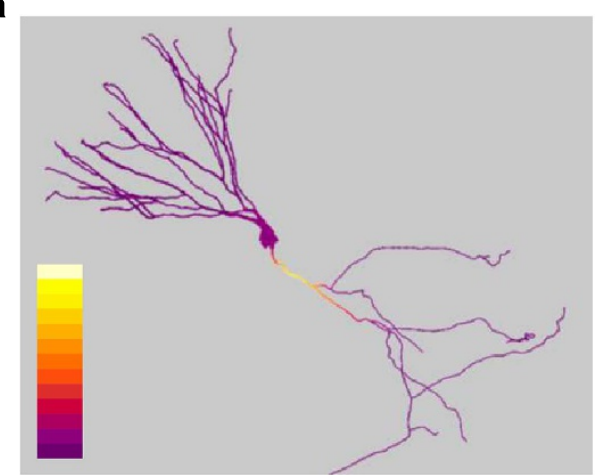

C

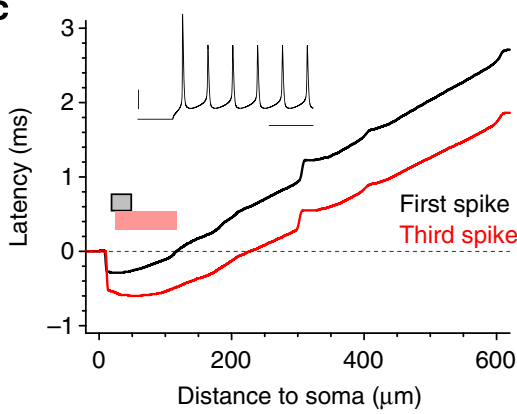

b

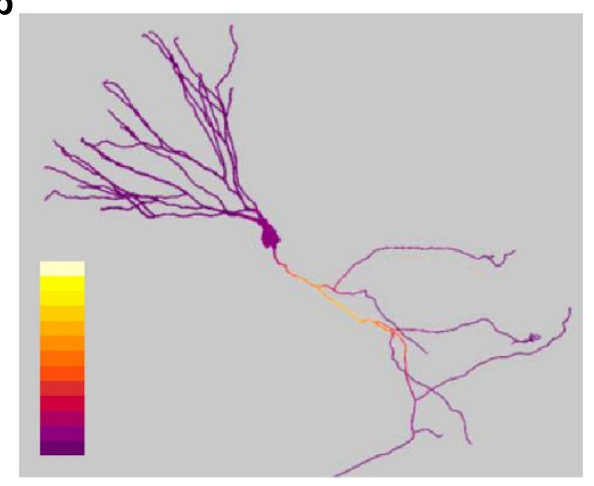

d

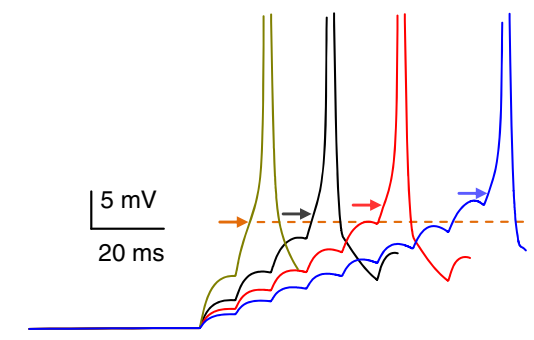

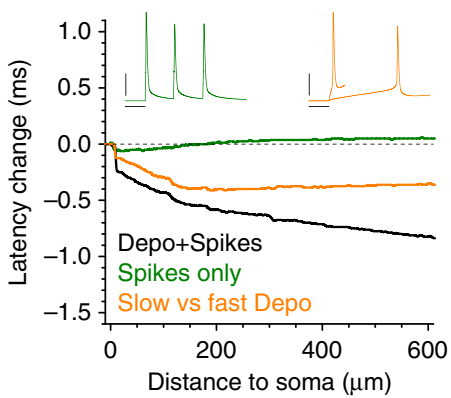

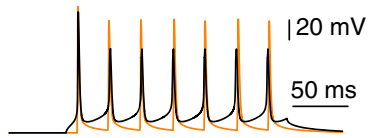

Depo+Spikes

Spikes only

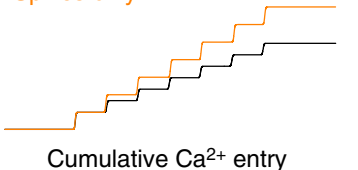

g

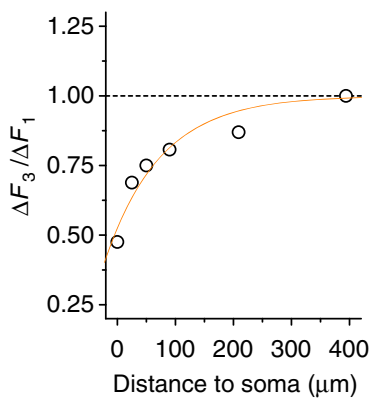

Figure 6 | A NEURON granule cell model points to excitation-dependent inactivation of $\mathbf{N a}^{+}$channels. (a) A modelled granule cell adapted from Schmidt-Hieber et al. ${ }^{54}$ and further complemented as in Scott et al. ${ }^{25}$ The colour-coded diagram (dV/dt values, colour scale bar 0-400 Vs ${ }^{-1}$ ) shows a snapshot at the time point following somatic depolarization (130 pA injection current) when the maximum depolarization rate $\left((\mathrm{dV} / \mathrm{d} t)_{\mathrm{max}}\right.$ the apparent spike-initiation onset) is reached anywhere in the axon. The area associated with the AP initiation can be seen in the initial axonal segment. (b) The snapshot as in a but during the third consecutive spike: the area associated with AP initiation can be seen clearly expanding away from the soma (colour scale bar $\left.0-250 \mathrm{Vs}^{-1}\right)$. (c) The $\left(t_{\mathrm{a}}-t_{\mathrm{s}}\right.$ ) latency plot obtained as in Fig. $2 \mathrm{~d}$ for the model shown in $\mathbf{a}, \mathbf{b}$. Colour bars show typical sites of initiation for the first (grey) and third (red) spikes (axonal areas corresponding to a range within $\sim 20 \%$ of the most negative latency values), as indicated. Scale bar for insets: $20 \mathrm{mV}, 50 \mathrm{~ms}$. (d) Somatic injection of synaptic current trains of varying intensity in the model demonstrates adaptive properties of the spiking threshold consistent with experiments shown in Fig. 1; arrows, spiking threshold determined as $\min \left(\mathrm{d}^{2} \mathrm{~V} / \mathrm{dt} \mathrm{t}^{2}\right), V_{\text {rest }}=-79 \mathrm{mV}$, dotted line, first spike threshold.

(e) The somatic excitation-induced change in $\left(t_{\mathrm{a}}-t_{\mathrm{s}}\right)$ latency (an indicator for alterations of the AP-initiation site) depends on depolarization and on the distance to the soma, rather than on spiking per se. In the three simulation examples, APs were induced by suprathreshold somatic depolarization (Depo + Spikes, black), and by 0.5 ms pulses only (Spikes only, green), and by constant subthreshold depolarization of varying intensity (Slow versus fast Depo, orange), as indicated. Scale bars for insets, $30 \mathrm{mV}, 20 \mathrm{~ms}$. (f) An example of the simulated AP-induced Ca ${ }^{2+}$ influx during somatic depolarization: such computations were made at different points throughout the axon. $(\mathbf{g})$ The ratio of $\mathrm{Ca}^{2+}$ increments evoked by the third and first consecutive APs is lowest near the soma ( $\sim 50 \%$ ) but reduces with larger distances to the soma. This is consistent with experimental observations (Fig. 5) implicating partial inactivation of $\mathrm{Na}^{+}$channels depending on somatic depolarization and distance from the soma. Line, single-exponent fitting.

becomes spread more evenly along the proximal axon in the course of somatic depolarization. In line with this suggestions, Monte Carlo simulations of latency measures predicted usedependent broadening of the proximal axonal segment, apparently with a contribution of spike deceleration in proximal segments ${ }^{32}$.

The most parsimonious cellular mechanism underlying these observations was partial inactivation of axonal $\mathrm{Na}^{+}$channels by somatic depolarization, which propagates electrotonically into the axon. Although this hypothesis appears to be a straightforward theoretical consequence of voltage-dependent channel kinetics and electrotonic propagation of somatic voltage into the axon, it has not been explored previously, either theoretically or empirically. To test this hypothesis further, we imaged axonal $\mathrm{Na}^{+}$and found that somatic depolarization (induced by direct current injection or via dendritic synaptic inputs) reduced 
AP-evoked axonal $\mathrm{Na}^{+}$entry, with the greatest effect in more proximal segments. This was fully consistent with the distancedependent $\mathrm{Na}^{+}$channel inactivation.

Another piece of experimental evidence implicating depolarization-dependent inactivation of $\mathrm{Na}^{+}$channels was obtained using axonal $\mathrm{Ca}^{2+}$ imaging. We have found that somatic excitation progressively reduces $\mathrm{Ca}^{2+}$ entry and that this effect weakens with the distance from the soma. This was opposite to what was expected from $\mathrm{K}^{+}$channel inactivation that increases $\mathrm{Ca}^{2+}$ entry upon depolarization ${ }^{28,39,45,46}$. We concluded, therefore, that depolarization- and distance-dependent partial inactivation of $\mathrm{Na}^{+}$channels dominates in modulating the AP-dependent $\mathrm{Ca}^{2+}$ entry in proximal MF segments. It remains an intriguing and open question whether our $\mathrm{Ca}^{2+}$ imaging results could also implicate use-dependent plasticity of local $\mathrm{Ca}^{2+}$ entry in the spiking mechanism control more directly, via the molecular cascades described recently ${ }^{42}$.

Interestingly, our previous observations indicated that somatic depolarization of granule cells could increase spike-evoked $\mathrm{Ca}^{2+}$ entry in proximal axonal segments ${ }^{26}$. However, these earlier experiments were carried out by distantly evoking antidromic spikes while holding the soma in voltage clamp. This must have curtailed depolarization-dependent $\mathrm{Na}^{+}$channel inactivation, thus in effect reproducing the 'Spikes only' scenario in our present study (Fig. 6e,f), probably through facilitation of depolarization-dependent $\mathrm{K}^{+}$channel inactivation. Finally, we asked whether our observations were consistent with the biophysics of spike generation and propagation in granule cell axons. We therefore explored a previously tested NEURON model of a fully reconstructed granule cell including the axon. Throughout the study, we were able to readily reproduce our experimental observations in a detailed compartmental model of a three-dimensional (3D) reconstructed granule cell, demonstrating a mechanistic link between distance-dependent $\mathrm{Na}^{+}$channel inactivation, expanded spike-initiation site, changes in axonal $\mathrm{Ca}^{2+}$ entry and use-dependent adaptation of the cellspiking threshold.

Synchronization of spiking activity among principal neurons has been thought as an essential part of neuronal information handling ${ }^{47}$ including conscious processing ${ }^{48}$. Our results in hippocampal granule cells lend further support to the view that the simple sum of excitatory inputs can produce different outcomes depending on the time course of summation, with highly synchronized inputs gaining an added effective weight $t^{7-9}$. Previously, the differences in geometry and position of the axonal AP-initiation site were found to underlie adaptation to particular spiking patterns among individual neurons in the nucleus laminaris of birds ${ }^{19}$. The present findings advance this concept further, suggesting that the spike-initiation region could be considered as a plastic rather than a fixed entity, not only in terms of long-term developmental or adaptive changes but also during the ongoing network activity. In line with this hypothesis, a very recent study has found that subtle use-dependent changes in the local $\mathrm{Na}^{+}$channel density and therefore spike-initiation site in cortical neurons could have a large influence on neuronal excitability ${ }^{16}$. It would be important to understand how universal this mechanism is among excitatory circuits of the brain.

\section{Methods}

Electrophysiology. All animal experimentation routines followed the UK Animals Scientific Procedures Act (1986) amended and adapted to comply with the European Directive 2010/63/EU on the Protection of Animals used for Scientific

Purposes. Acute 350- $\mu \mathrm{m}$ hippocampal slices from 3- to 4-week-old male SpragueDawley rats were transferred to a submersion-type recording chamber (Scientific Systems Design, NJ, USA) and superfused with (mM) $124 \mathrm{NaCl}, 2.5 \mathrm{KCl}, 2 \mathrm{CaCl}_{2}$, $1.3 \mathrm{MgSO}_{4}, 26 \mathrm{NaHCO}_{3}$ and 10 glucose and were bubbled with $95 \% \mathrm{O}_{2} / 5 \% \mathrm{CO}_{2}$. The slice orientation that helps to avoid cutting MFs was detailed previously ${ }^{41}$. The internal solution included (mM) the following: $135 \mathrm{~K}$ methanesulfonate, $2 \mathrm{MgCl}_{2}$, 10 HEPES, 10 di(Tris)-Phosphocreatine, 4 NaATP, 0.4 NaGTP and fluorophores as indicated. Dentate granule cells were discarded if their resting potential increased above $-70 \mathrm{mV}$ in current clamp mode. Receptor antagonists were purchased from Tocris Cookson, and fluorescent probes were purchased from Invitrogen. We used the procedures detailed earlier ${ }^{25}$ to track and record from granule cell axons. In brief, we traced axons in the Alexa emission channel (up to $150-200 \mu \mathrm{m}$ deep in the slice) and approached a selected fragment with a patch pipette, in voltageclamp configuration, applying negative pressure to achieve loose patch (100-200 MOhm seal resistance). Experiments were carried out either at $\sim 25$ or $\sim 33^{\circ} \mathrm{C}$, as indicated.

Two-photon excitation fluorescence imaging. We used a Radiance 2000 or 2100 (Zeiss-Bio-Rad) imaging system optically linked to a MaiTai (SpectraPhysicsNewport) femtosecond-pulsed infrared laser (in London), a FV10-MP (Olympus) system linked to a Vision-S (Coherent) laser (in Bonn) or a confocal scanning unit (LCS Leica SP5 II, Leica Microsystems, Mannheim, Germany) attached to an upright microscope (DM6000CFS, Leica Microsystems; $25 \times$ objective, HCX IRAPO L $25 \times$, numerical aperture 0.95, Leica Microsystems) linked to a MaiTai laser (in Alicante). The imaging systems were integrated with patch-clamp electrophysiology. Single orthodromic escape action currents were evoked by a 2-ms command voltage pulse. Recording sweeps (normally 500-ms long) were collected at 5 or $20 \mathrm{kHz}$ (dual-patch recordings) with 30 -s or 1-min intervals. Granule cells held in whole-cell mode were loaded with two fluorophores: a morphological tracer Alexa Fluor $594(20-40 \mu \mathrm{M})$ and either the low-affinity $\mathrm{Na}^{+}$indicator SBFI $(1 \mathrm{mM})$ or the high-affinity $\mathrm{Ca}^{2+}$ indicator Fluo-4 $(200 \mu \mathrm{M})$. Fluorophores were excited in two-photon mode at $\lambda_{\mathrm{x}}^{2 P}=800 \mathrm{~nm}$. The technique to trace MFs into the CA3 region $500-1,000 \mu \mathrm{m}$ from the soma has been detailed earlier ${ }^{41}$. The axon was imaged at the maximal optical resolution $(\sim 0.2 \mu \mathrm{m}, 70 \mathrm{~nm}$ per pixel). Experiments involving axon tracing and imaging were carried out at $25^{\circ} \mathrm{C}$ or $33^{\circ} \mathrm{C}$, as indicated. The $\mathrm{Ca}^{2+}$-dependent Fluo-4 fluorescence signal (Fig. 5) was quantified as $\Delta F /$ $F_{\mathrm{B}}=\left(F-F_{\text {pre }}\right) /\left(F_{\text {pre }}-F_{0}\right)$, where $F_{0}$ denotes the background fluorescence and $F_{\mathrm{B}}=F_{\text {pre }}-F_{0}$ the pre-stimulus baseline axonal fluorescence. For $\mathrm{Ca}^{2+}$ transients evoked by precisely timed spikes generated in response to brief depolarizing pulses (Fig. $5 \mathrm{c}-\mathrm{e}$ ), the ratio of $\mathrm{Ca}^{2+}$-dependent fluorescence increments during the spike train are given as $\Delta F_{3} / \Delta F_{1}$ for the third and first spikes. When $\mathrm{Ca}^{2+}$ transients were elicited by depolarization-induced and therefore variable spike trains (Fig. 5f,g), the ratio of early fluorescence increments $F_{\text {early }}(0-40 \mathrm{~ms}$ after stimulus onset) and delayed increments $F_{\text {late }}(40-200 \mathrm{~ms}$ after stimulus onset) was calculated: $\left(F_{\text {late }}-F_{\mathrm{B}}\right) /\left(F_{\text {early }}-F_{\mathrm{B}}\right)$.

Action potential-evoked $\mathrm{Na}^{+}$entry in response to synaptic input (Fig. $4 \mathrm{~g}-\mathrm{i}$ ) was estimated from axonal SBFI fluorescence $10-30 \mu \mathrm{m}$ away from the soma. SBFI fluorescence was first normalized to that of the sodium-insensitive morphological marker Alexa Fluor 594 and then normalized to baseline. Individual fluorescence traces with low or high AP latency, three to five trials for each, were then aligned at the AP peak and averaged. Image analysis was performed on stacks of stored linescan images using ImageJ (NIH) macros or in Matlab (Mathworks). False-colour tables and averaged images were used for illustration purposes but the quantitative analyses always dealt with the original (grey level) pixel brightness values. In most experiments, we reconstructed the axon trajectory using a collage of high-resolution Kalmanfiltered $z$-stacks $15-20 \mu \mathrm{m}$ deep using 10-scan average frames.

Quantifying axonal $\mathrm{Na}^{+}$entry. To translate SBFI (sodium-binding benzofuran isophthalate) fluorescence into the internal $\mathrm{Na}^{+}$concentration $\left(\left[\mathrm{Na}^{+}\right]_{\text {in }}\right)$ time course, we considered the explicit kinetics of $\mathrm{Na}^{+}$entry, binding and extrusion, by adapting the multicomponent single-compartment kinetic model, which was extensively tested earlier ${ }^{41}$ (see below). As such models do not assume steady state and thus require the knowledge of the indicator binding on-rate, $k_{\mathrm{on}}^{\mathrm{SBFI}}$ (in addition to the known $K_{\mathrm{D}}$ ), we attempted to estimate its value first. To achieve this, we exploited the fact that the typical rise time of SBFI fluorescence following a single spike is $20-30 \mathrm{~ms}$, whereas active $\mathrm{Na}^{+}$extrusion mechanisms act on a much slower timescale. Indeed, classical measurements in giant axons ${ }^{49}$ indicate the maximal achievable axonal $\mathrm{Na}^{+}$efflux rate in the range of $20-40 \mathrm{pmol} \mathrm{cm}^{-2} \mathrm{~s}^{-1}$, which translates into $1.6-3.2 \mathrm{mM} \mathrm{s}^{-1}$ for a $\sim 0.5-\mu \mathrm{m}$-wide axon (comparable to $\mathrm{MFs}$ ), in agreement with measurements in granule cell axons ${ }^{50}$. In other words, $\mathrm{Na}^{+}$extrusion post spike should have a negligible effect on $\left[\mathrm{Na}^{+}\right]_{\text {in }}$ time course during spike-evoked $\mathrm{Na}^{+}$influx $\left(1 \mathrm{~ms}\right.$ scale) or $\mathrm{Na}^{+}$binding to SBFI (20- to 30 $\mathrm{ms}$ scale). Furthermore, a multicompartmental model of a granule cell ${ }^{41}$ predicted that $\mathrm{Na}^{+}$equilibration post spike because of diffusion along the axon within 20 - to 30 -ms post entry should have little influence $(<5 \%)$ on the longitudinal $\left[\mathrm{Na}^{+}\right]_{\text {in }}$ profile (not shown). These considerations allowed us to constrain the $\left[\mathrm{Na}^{+}\right]_{\text {in }}$ kinetic, for at least $20-30 \mathrm{~ms}$ post entry, to a single free parameter, $k_{\mathrm{on}}^{\mathrm{SBI}}$. We therefore imaged SBFI fluorescence near the AP-initiation site in response to a somatic voltage step from -75 to $+10 \mathrm{mV}$ (thus evoking a very brief pulse of $\mathrm{Na}^{+}$entry through rapidly inactivating $\mathrm{Na}^{+}$channels). The rising phase kinetics of the SBFI-dependent fluorescence signal was best fitted with $k_{\mathrm{on}}^{\mathrm{SBFI}}=$ $2.0 \mathrm{M}^{-1} \mathrm{~ms}^{-1}$ (Supplementary Fig. 3a).

Equipped with this value, we were able to evaluate the remaining kinetic parameters, the $\mathrm{Na}^{+}$extrusion rate $P_{\mathrm{Na}}$ and the amount of $\mathrm{Na}^{+}$entry expressed as the spike-evoked $\left[\mathrm{Na}^{+}\right]_{\text {in }}$ increment $\Delta \mathrm{Na}$. To achieve this, we recorded SBFI 
fluorescence near the AP-initiation site under two complementary protocols, with five APs at $20 \mathrm{~Hz}$ and $100 \mathrm{APs}$ at $50 \mathrm{~Hz}$ (by applying 2-ms depolarizing pulses), as detailed earlier ${ }^{41,51}$. On the timescale of these experiments, residual $\mathrm{Na}^{+}$escape because of the $\left[\mathrm{Na}^{+}\right]_{\text {in }}$ gradient along the axon was well approximated by a firstorder removal rate of $\sim 0.8 \mathrm{~s}^{-1}$ (Supplementary Fig. 3b,c). The remaining two adjustable parameters, $\Delta \mathrm{Na}$ and $P_{\mathrm{Na}}$, were therefore reasonably constrained between the two protocols. Furthermore, the influences of $\Delta \mathrm{Na}$ and $P_{\mathrm{Na}}$ on the $\left[\mathrm{Na}^{+}\right]_{\text {in }}$ kinetics were in effect mutually independent (that is, orthogonal) over the tested physiological range: $\Delta \mathrm{Na}$ scaled with the fluorescence (inverse) increment signal $\Delta F / F$, whereas $P_{\mathrm{Na}}$ defined predominantly the signal (inverse) decay. The fitting procedure was therefore relatively straightforward, giving the best fit at $P_{\mathrm{Na}} \sim 0.0022 \mathrm{~ms}^{-1}$ and $\Delta \mathrm{Na} \sim 0.4 \mathrm{mM}$, which was in correspondence with the axonal $\mathrm{Na}^{+}$entry estimated in cortical pyramidal cells ${ }^{12}$. These estimates enabled us to calculate the $\left[\mathrm{Na}^{+}\right]_{\text {in }}$ time course near the AP-initiation site (Supplementary Fig. $3 b, c)$.

Multicomponent model of local $\mathrm{Na}^{+}$dynamics. To evaluate the intra-axonal $\mathrm{Na}^{+}$kinetics based on SBFI fluorescence data, we used an explicit finite-difference kinetic scheme $e^{41,52}$ incorporating $\mathrm{Na}^{+}$entry rate $j_{\mathrm{Na}}$, the binding-unbinding reactions with the indicator $S B F I$, and the $\mathrm{Na}^{+}$removal rate $P_{\mathrm{Na}}$ :

$$
\begin{aligned}
\partial\left[\mathrm{Na}^{+}\right] / \partial t= & j_{\mathrm{Na}}+k_{\mathrm{off}}^{\mathrm{SBFI}}[\mathrm{NaSBFI}]-k_{\mathrm{on}}^{\mathrm{SBFI}}\left[\mathrm{Na}^{+}\right][\mathrm{SBFI}] \\
& -\left(P_{\mathrm{Na}}+D_{\mathrm{Na}}\right)\left(\left[\mathrm{Na}^{+}\right]-\left[\mathrm{Na}^{+}\right]_{0}\right),
\end{aligned}
$$

with the mass conservation rules:

$$
[\mathrm{SBFI}]_{\mathrm{tot}}=[\mathrm{NaSBFI}]+[\mathrm{SBFI}] \text {, and }[\mathrm{Na}]_{\mathrm{tot}}=\left[\mathrm{Na}^{+}\right]+[\mathrm{NaSBFI}] \text {, }
$$

where brackets denote concentrations, NaSBFI stands for the Na-bound indicator, $P_{\mathrm{Na}}$ in equation (1) is the $\mathrm{Na}^{+}$extrusion rate, $D_{\mathrm{Na}}$ in equation (1) is its longitudinal diffusion escape rate and index 'tot' denotes total amount.

The AP-evoked $\mathrm{Na}^{2+}$ influx rate $j_{\mathrm{Na}}$ was approximated by the Gaussian ${ }^{52,53}$

$$
j_{\mathrm{Na}}=\frac{\Delta\left[\mathrm{Na}^{+}\right]_{\mathrm{tot}}}{\sigma \sqrt{2 \pi}} \exp \left(-\frac{\left(t-t_{0}\right)^{2}}{2 \sigma^{2}}\right),
$$

roughly representing the AP waveform, with the MF spike half-width of $\sigma \approx 0.5 \mathrm{~ms}$ (ref. 39), onset at $t_{0}$ and the time integral of $\Delta\left[\mathrm{Na}^{+}\right]_{\text {tot }}$ reflecting total $\mathrm{Na}^{+}$entry. Twofold variations in $\sigma$ values in equation (3) had negligible influence on the kinetics of $\mathrm{Na}^{+}$-SBFI binding.

Once the $k_{\mathrm{on}}^{\mathrm{SBFI}}$ and the range of $D_{\mathrm{Na}}$ have been established (the effect of $D_{\mathrm{Na}}$ was negligible, data not shown), the model operated with only two adjustable (free) parameters: $\Delta\left[\mathrm{Na}^{+}\right]_{\text {tot }}$ and $P_{\mathrm{Na}}$. However, varying either $\Delta\left[\mathrm{Ca}^{2+}\right]_{\text {tot }}$ or $P_{\mathrm{Na}}$ had virtually independent effects on, respectively, the calculated amplitude $(\Delta F / F)$ and decay of fluorescent responses. Each of the two parameters could be, therefore, constrained by a straightforward fitting procedure that would match the calculated and the experimental fluorescence, as detailed earlier ${ }^{41}$.

Compartmental NEURON model of a dentate granule cell. We used a NEURON model of a fully reconstructed dentate granule cell ${ }^{54}$ (cell no 7 in the cited reference), which could be directly imported from the database at SenseLab, ModelDB $=95960$ at http://senselab.med.yale.edu/modeldb. Passive axon parameters were adopted from measurements made earlier ${ }^{25}$. Axonal axial resistance was set to $80 \mathrm{Ohm} \mathrm{cm}$. Sodium and potassium channel kinetics was implemented as described ${ }^{31}$ and distributed as a function of distance from the soma (Supplementary Fig. 6). The channel conductance distribution was adjusted to reproduce experimental observations (without introducing additional membrane conductances). The reverse potentials for $\mathrm{Na}^{+}, \mathrm{K}^{+}$and leak currents were set to $58,-95$ and $-80 \mathrm{mV}$, respectively. Axon collateral diameters were set at $0.25 \mu \mathrm{m}$, their axial resistance was $300 \mathrm{Ohm} \mathrm{cm}$ and their maximum conductances for $\mathrm{Na}^{+}$ and $\mathrm{K}^{+}$were, respectively, 0.012 and $0.003 \mathrm{~S} \mathrm{~cm}^{-2}$. Action potentials were elicited by somatic current injections as illustrated. In accord with experimental measurements, AP initiation in a particular section of the cell was considered to occur at the time when the rate of depolarization $(\mathrm{d} V / \mathrm{d} t)$ reached its maximum value $(\mathrm{d} V / \mathrm{d} t)_{\max }$. The site of AP initiation was defined as the first (earliest) section initiating an $\mathrm{AP}$ in response to current injection. A latency plot equivalent to experimental protocols was calculated using the spatial distribution of $\mathrm{AP}$ initiation onsets (Fig. 6). To monitor $\mathrm{Ca}^{2+}$ influx along the axon, a generic $\mathrm{Ca}^{2+}$ channel model was adopted from the study by Royeck et al. ${ }^{43}$ (ModelDB, accession: 115356) and distributed homogeneously at a relatively low density $\left(100 \mathrm{nS} \mathrm{cm}^{-2}\right)$. As our simulations were focused on the total $\mathrm{Ca}^{2+}$ entry (increments) rather than the kinetics of free $\mathrm{Ca}^{2+}$, intracellular $\mathrm{Ca}^{2+}$ buffering and extrusion were ignored in the model.

\section{References}

1. Henze, D. A. \& Buzsaki, G. Action potential threshold of hippocampal pyramidal cells in vivo is increased by recent spiking activity. Neuroscience 105, 121-130 (2001)

2. Fricker, D., Verheugen, J. A. \& Miles, R. Cell-attached measurements of the firing threshold of rat hippocampal neurones. J. Physiol. 517(Pt 3): 791-804 (1999).
3. Azouz, R. \& Gray, C. M. Dynamic spike threshold reveals a mechanism for synaptic coincidence detection in cortical neurons in vivo. Proc. Natl Acad. Sci. USA 97, 8110-8115 (2000).

4. de Polavieja, G. G., Harsch, A., Kleppe, I., Robinson, H. P. \& Juusola, M. Stimulus history reliably shapes action potential waveforms of cortical neurons. J. Neurosci. 25, 5657-5665 (2005).

5. Prescott, S. A., Ratte, S., De Koninck, Y. \& Sejnowski, T. J. Nonlinear interaction between shunting and adaptation controls a switch between integration and coincidence detection in pyramidal neurons. J. Neurosci. 26, 9084-9097 (2006).

6. Yu, Y., Shu, Y. \& McCormick, D. A. Cortical action potential backpropagation explains spike threshold variability and rapid-onset kinetics. J. Neurosci. 28, 7260-7272 (2008).

7. Azouz, R. \& Grey, C. M. Adaptive coincidence detection and dynamic gain control in visual cortical neurons in vivo. Neuron 37, 513-523 (2003).

8. Crowley, J. J., Fioravante, D. \& Regehr, W. G. Dynamics of fast and slow inhibition from cerebellar golgi cells allow flexible control of synaptic integration. Neuron 63, 843-853 (2009).

9. Platkiewicz, J. \& Brette, R. Impact of fast sodium channel inactivation on spike threshold dynamics and synaptic integration. PLoS Comput. Biol. 7, e1001129 (2011).

10. Stuart, G., Spruston, N., Sakmann, B. \& Hausser, M. Action potential initiation and backpropagation in neurons of the mammalian CNS. Trends Neurosci. 20, 125-131 (1997).

11. Palmer, L. M. \& Stuart, G. J. Site of action potential initiation in layer 5 pyramidal neurons. J. Neurosci. 26, 1854-1863 (2006).

12. Kole, M. H. P. et al. Action potential generation requires a high sodium channel density in the axon initial segment. Nat. Neurosci. 11, 178-186 (2008).

13. Hu, W. et al. Distinct contributions of $\mathrm{Na}_{\mathrm{v}} 1.6$ and $\mathrm{Na}_{\mathrm{v}} 1.2$ in action potential initiation and backpropagation. Nat. Neurosci. 12, 996-1002 (2009).

14. Foust, A., Popovic, M., Zecevic, D. \& McCormick, D. A. Action potentials initiate in the axon initial segment and propagate through axon collaterals reliably in cerebellar Purkinje neurons. J. Neurosci. 30, 6891-6902 (2010).

15. Colbert, C. M. \& Pan, E. Ion channel properties underlying axonal action potential initiation in pyramidal neurons. Nat. Neurosci. 5, 533-538 (2002).

16. Baranauskas, G., David, Y. \& Fleidervish, I. A. Spatial mismatch between the $\mathrm{Na}^{+}$flux and spike initiation in axon initial segment. Proc. Natl Acad. Sci. USA 110, 4051-4056 (2013).

17. Grubb, M. S. \& Burrone, J. Activity-dependent relocation of the axon initial segment fine-tunes neuronal excitability. Nature 465, 1070-1074 (2010).

18. Kuba, H., Oichi, Y. \& Ohmori, H. Presynaptic activity regulates $\mathrm{Na}^{+}$channel distribution at the axon initial segment. Nature 465, 1075-1078 (2010).

19. Kuba, H., Ishii, T. M. \& Ohmori, H. Axonal site of spike initiation enhances auditory coincidence detection. Nature 444, 1069-1072 (2006).

20. Popovic, M. A., Foust, A. J., McCormick, D. A. \& Zecevic, D. The spatiotemporal characteristics of action potential initiation in layer 5 pyramidal neurons: a voltage imaging study. J. Physiol. 589, 4167-4187 (2011).

21. Ma, Y. \& Huguenard, J. R. Reemerging role of cable properties in action potential initiation. Proc. Natl Acad. Sci. USA 110, 3715-3716 (2013).

22. Salin, P. A., Scanziani, M., Malenka, R. C. \& Nicoll, R. A. Distinct short-term plasticity at two excitatory synapses in the hippocampus. Proc. Natl Acad. Sci. USA 93, 13304-13309 (1996).

23. Mori-Kawakami, F., Kobayashi, K. \& Takahashi, T. Developmental decrease in synaptic facilitation at the mouse hippocampal mossy fibre synapse. J. Physiol. 553, 37-48 (2003).

24. Pelkey, K. A., Topolnik, L., Lacaille, J. C. \& McBain, C. J. Compartmentalized $\mathrm{Ca}^{2+}$ channel regulation at divergent mossy-fiber release sites underlies target cell-dependent plasticity. Neuron 52, 497-510 (2006).

25. Scott, R., Ruiz, A., Henneberger, C., Kullmann, D. M. \& Rusakov, D. A. Analog modulation of mossy fiber transmission is uncoupled from changes in presynaptic $\mathrm{Ca}^{2+}$. J. Neurosci. 28, 7765-7773 (2008).

26. Ruiz, A. et al. GABAA receptors at hippocampal mossy fibers. Neuron 39, 961-973 (2003).

27. Alle, H. \& Geiger, J. R. Combined analog and action potential coding in hippocampal mossy fibers. Science 311, 1290-1293 (2006).

28. Geiger, J. R. \& Jonas, P. Dynamic control of presynaptic $\mathrm{Ca}^{2+}$ inflow by fastinactivating $\mathrm{K}^{+}$channels in hippocampal mossy fiber boutons. Neuron $\mathbf{2 8}$, 927-939 (2000).

29. Schmidt-Hieber, C. \& Bischofberger, J. Fast sodium channel gating supports localized and efficient axonal action potential initiation. J. Neurosci. 30, 10233-10242 (2010).

30. Mistry, R., Dennis, S., Frerking, M. \& Mellor, J. R. Dentate gyrus granule cell firing patterns can induce mossy fiber long-term potentiation in vitro. Hippocampus 21, 1157-1168 (2011).

31. Schmidt-Hieber, C., Jonas, P. \& Bischofberger, J. Action potential initiation and propagation in hippocampal mossy fibre axons. J. Physiol. 586, 1849-1857 (2008). 
32. Kress, G. J., Dowling, M. J., Meeks, J. P. \& Mennerick, S. High threshold, proximal initiation, and slow conduction velocity of action potentials in dentate granule neuron mossy fibers. J. Neurophysiol. 100, 281-291 (2008).

33. Clark, B. A., Monsivais, P., Branco, T., London, M. \& Hausser, M. The site of action potential initiation in cerebellar Purkinje neurons. Nat. Neurosci. 8, 137-139 (2005).

34. Ellerkmann, R. K., Riazanski, V., Elger, C. E., Urban, B. W. \& Beck, H. Slow recovery from inactivation regulates the availability of voltage-dependent $\mathrm{Na}^{+}$ channels in hippocampal granule cells, hilar neurons and basket cells. J. Physiol. 532, 385-397 (2001).

35. Engel, D. \& Jonas, P. Presynaptic action potential amplification by voltagegated $\mathrm{Na}^{+}$channels in hippocampal mossy fiber boutons. Neuron 45, 405-417 (2005).

36. Meeks, J. P., Jiang, X. \& Mennerick, S. Action potential fidelity during normal and epileptiform activity in paired soma-axon recordings from rat hippocampus. J. Physiol. 566, 425-441 (2005).

37. Sasaki, T., Matsuki, N. \& Ikegaya, Y. Action-potential modulation during axonal conduction. Science 331, 599-601 (2011).

38. Alle, H., Roth, A. \& Geiger, J. R. Energy-efficient action potentials in hippocampal mossy fibers. Science 325, 1405-1408 (2009).

39. Bischofberger, J., Geiger, J. R. \& Jonas, P. Timing and efficacy of $\mathrm{Ca}^{2+}$ channel activation in hippocampal mossy fiber boutons. J. Neurosci. 22, 10593-10602 (2002).

40. Rose, C. R., Kovalchuk, Y., Eilers, J. \& Konnerth, A. Two-photon $\mathrm{Na}^{+}$imaging in spines and fine dendrites of central neurons. Pflugers Arch. 439, 201-207 (1999).

41. Scott, R. \& Rusakov, D. A. Main determinants of presynaptic $\mathrm{Ca}^{2+}$ dynamics at individual mossy fiber-CA3 pyramidal cell synapses. J. Neurosci. 26, 7071-7081 (2006)

42. Bender, K. J. \& Trussell, L. O. Axon initial segment $\mathrm{Ca}^{2+}$ channels influence action potential generation and timing. Neuron 61, 259-271 (2009).

43. Royeck, M. et al. Role of axonal NaV1.6 sodium channels in action potential initiation of CA1 pyramidal neurons. J. Neurophysiol. 100, 2361-2380 (2008).

44. Toth, K., Suares, G., Lawrence, J. J., Philips-Tansey, E. \& McBain, C. J. Differential mechanisms of transmission at three types of mossy fiber synapse. J. Neurosci. 20, 8279-8289 (2000).

45. Shu, Y., Hasenstaub, A., Duque, A., Yu, Y. \& McCormick, D. A. Modulation of intracortical synaptic potentials by presynaptic somatic membrane potential. Nature 441, 761-765 (2006).

46. Christie, J. M., Chiu, D. N. \& Jahr, C. E. $\mathrm{Ca}^{2+}$-dependent enhancement of release by subthreshold somatic depolarization. Nat. Neurosci. 14, 62-68 (2011).

47. Fell, J. \& Axmacher, N. The role of phase synchronization in memory processes. Nat. Rev. Neurosci. 12, 105-118 (2011).

48. Dehaene, S. \& Changeux, J. P. Experimental and theoretical approaches to conscious processing. Neuron 70, 200-227 (2011).

49. De Weer, P. Effects of intracellular ADP and Pi on the sodium pump of squid giant axon. Nature 226, 1251-1252 (1970).
50. Regehr, W. G. Interplay between sodium and calcium dynamics in granule cell presynaptic terminals. Biophys. J. 73, 2476-2488 (1997).

51. Rusakov, D. A., Saitow, F., Lehre, K. P. \& Konishi, S. Modulation of presynaptic $\mathrm{Ca} 2+$ entry by AMPA receptors at individual GABAergic synapses in the cerebellum. J. Neurosci. 25, 4930-4940 (2005).

52. Rusakov, D. A., Wuerz, A. \& Kullmann, D. M. Heterogeneity and specificity of presynaptic $\mathrm{Ca}^{2+}$ current modulation by mGluRs at individual hippocampal synapses. Cereb. Cortex 14, 748-758 (2004).

53. Sabatini, B. L. \& Regehr, W. G. Optical measurement of presynaptic calcium currents. Biophys. J. 74, 1549-1563 (1998).

54. Schmidt-Hieber, C., Jonas, P. \& Bischofberger, J. Subthreshold dendritic signal processing and coincidence detection in dentate gyrus granule cells. J. Neurosci. 27, 8430-8441 (2007).

\section{Acknowledgements}

This work was supported by the Wellcome Trust Principal Fellowship, Medical Research Council (UK), Biology and Biotechnology Research Council (UK), European Research Council Advanced Grant, FP7 BM1001 COST Action (D.A.R.); Ramon y Cajal Fellowship and Spanish Ministerio de Ciencia e Innovación Grant, SAF2010-20604 (R.S.S.); Human Frontier Science Program, UCL Excellence Fellowship, and the NRW-Rückkehrerprogramm (C.H.). We would like to thank Dimitri Kullmann, Dominique Debanne, Miguel Maravall and Arnaud Ruiz for their valuable comments and suggestions, and Carol Serra for technical assistance.

\section{Author contributions}

R.S.S., C.H., R.P., S.A. and T.P.J. performed experimental studies and analyses, C.H. and D.A.R. carried out modelling studies; D.A.R. narrated the study, which was subsequently contributed by all the authors.

\section{Additional information}

Supplementary Information accompanies this paper at http://www.nature.com/ naturecommunications

Competing financial interests: The authors declare no competing financial interests.

Reprints and permission information is available online at http://npg.nature.com/ reprintsandpermissions/

How to cite this article: Scott, R. S. et al. Neuronal adaptation involves rapid expansion of the action potential initiation site. Nat. Commun. 5:3817 doi: 10.1038/ncomms4817 (2014).

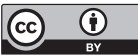

This work is licensed under a Creative Commons Attribution 3.0 Unported License. The images or other third party material in this article are included in the article's Creative Commons license, unless indicated otherwise in the credit line; if the material is not included under the Creative Commons license, users will need to obtain permission from the license holder to reproduce the material. To view a copy of this license, visit http://creativecommons.org/licenses/by/3.0/ 